\title{
Modeling lactation curves of Polish Holstein-Friesian cows. Part I: The accuracy of five lactation curve models
}

KEY WORDS: dairy cow, lactation curve, multiple-trait prediction method, goodness of fit

Received 22 June 2012

Revised 18 February 2013

Accepted

${ }^{1}$ Corresponding author:

e-mail: rzmindur@cyf-kr.edu.pl

\author{
A. Otwinowska-Mindur ${ }^{1}$, E. Ptak, W. Jagusiak, and A. Satoła \\ University of Agriculture in Krakow, Department of Genetics and Animal Breeding \\ al. Mickiewicza 24/28, 30-059 Kraków, Poland
}

\begin{abstract}
The objective of this study was to compare five mathematical functions used for modeling lactation curves and to choose the most suitable one for Polish Holstein-Friesian cows. The data used were 1,944,818; 1,548,700; and 1,081,107 test-day milk yields from 220,487 first, 181,165 second, and 128,774 third lactations. Five models were fitted to the test-day data: the Ali and Schaeffer (ALI), Guo (GUO), and Wilmink (WIL) functions, and thirdorder (LEG3), and fourth-order (LEG4) Legendre polynomials. The milk lactation curves were fitted using a multiple-trait prediction method. Several criteria based on the analysis of residuals were used to compare the models. Of the five models, five-parameter functions (ALI and LEG4) gave the best goodness of fit for standard lactations (305-d), whereas three-parameter functions (GUO and WIL) were the worst. For extended lactations (400-d), the ALI function ensured the most correct prediction.
\end{abstract}

\section{Introduction}

The genetic evaluation of dairy sires and cows for production traits has long been based on the analysis of 305-d lactation yields. In the last two decades, a great deal of effort has been devoted to investigating the direct use of test-day (TD) yields in the genetic evaluation of dairy cattle. The advantages of the TD model over an approach using 305-d lactation yields are now widely recognized. Nevertheless, dairymen traditionally rely on 305-d information in taking management decisions, so their demand for data on lactation yields would still need to be satisfied (Ptak and Schaeffer, 1993; Druet et al., 2003).

The test interval method (TIM) has been a standard tool for calculating a 305-d lactation yield from TD yields measured at approximately 30-d intervals throughout the lactation. With special adjustments for first and last TD yields, TIM has been an unbiased measure of actual 305-d yields (Schaeffer and Jamrozik, 1996; Norman et al., 1999). Other methods, e.g. best prediction (VanRaden, 1997) and multiple-trait procedure (Schaeffer and Jamrozik, 1996), have also been employed to predict a 305-d milk yield. The best prediction (BP) is a computational method derived from a selection index. It uses observed yields to predict daily yields that are not observed. The lactation yield is then a sum of all daily yields. If TD yields are multivariate normal with known means and (co)variances, then BP is the most reliable (VanRaden, 1997; Cole et al., 2009). The multiple-trait procedure (MTP) offers 
a possibility to estimate lactation curve parameters for milk, fat, and protein in each lactation of a cow. In solving MTP equations, (co)variances among traits, (co)variances among the curve parameters, and the parameters of a so-called "standard curve" are used. The "standard curve" is the lactation curve for cows with the same production characteristics: i.e., cows calving at a similar age in the same season, and being in the same lactation (Schaeffer and Jamrozik, 1996).

A typical lactation curve has an ascending phase to a peak (in the first 30 to 50 days post partum), followed by a descending phase (until a cow is dried off). Several parametric models, such as Wood (1967), Wilmink (1987), or Ali and Schaeffer (1987), have been developed to describe the lactation curve pattern for milk production. These functions differ chiefly in the type of regression (linear or nonlinear), the number of parameters, and the degree of associations with the main characteristics of a typical lactation pattern: i.e., peak yield, time at peak, and persistency (Macciotta et al., 2005). Legendre polynomials have offered an alternative to these functions. Models with Legendre polynomials as regressions are orthogonal, therefore they show better convergence than parametric models. To fit the shape of a lactation curve correctly, higher-order Legendre polynomials are required. Recently, splines have been introduced as a good replacement for Legendre polynomials, mainly because of their limited sensitivity to data and higher flexibility in fitting lactation curves. Splines are a type of segmented regression in which the curve is divided into several segments, joined at points called knots, each fitted with different polynomials. The problems with using splines include increased computational complexity and the difficulty of choosing the optimal number and placement of knots (Silvestre et al., 2006; Bohmanova et al., 2008; Macciotta et al., 2010).

The main objective of modeling the lactation curve is to predict the yield on each day of lactation as accurately as possible. The usefulness of any mathematical model depends on how well it can mimic the biological process of milk production and adjust for factors affecting it (Olori et al., 1999). During the past decades, the modeling of lactation curves has been the subject of many studies (Olori et al., 1999; Druet et al., 2003; Macciotta et al., 2005; Quinn et al., 2005; Silvestre et al., 2006; Dematawewa et al., 2007; Macciotta et al., 2010). An appropriate model of the lactation curve provides summary information about dairy production, which is useful in making management and breeding decisions relative to health monitoring or individual feeding, for example. In recent years, lactation curve models have been used in the genetic evaluation of dairy cattle (Olori et al., 1999; Macciotta et al., 2005).

Over the last decade, the duration of lactation has been extended beyond 305 days in some cow populations, with the average lactation lasting about 30 days longer (Vargas et al., 2000; Dematawewa et al., 2007). Breeding cows that lactate longer may bring more profit to farmers because such cows are less exposed to post partum metabolic diseases or difficult calvings, while producing the same lifetime amount of milk (Cole et al., 2009). Almost all uses of lactation models reported in the literature have been for 305-d or shorter lactations, with rare exceptions for longer ones (Vargas et al., 2000; Dematawewa et al., 2007).

The objective of the present study was to (1) compare five mathematical functions used for modeling curves of standard (305-d) and extended (400-d) lactations, and (2) choose the most suitable function for describing the two types of curves for Polish Holstein-Friesian cows.

\section{Material and methods}

The study used data on $1,944,818 ; 1,548,700$; and 1,081,107 test-day (TD) milk yields from 220,487 first, 181,165 second, and 128,774 third lactations, respectively. Data were collected for 434,726 Polish Holstein-Friesian cows in 21,486 herds. The average herd size was 21 cows. The data were held in the Polish national recording system SYMLEK, and were made available by the Polish Federation of Cattle Breeders and Dairy Farmers.

The following restrictions were imposed on the data:

1. Age at first, second, and third calving in the range of $18-48,29-65$, and $41-75$ months, respectively,

2. Test days (TD) per lactation per cow between 4 and 15 ,

3. Days in milk (DIM) between 5 and 400,

4. TD milk yields less than or equal to $85 \mathrm{~kg}$ of milk.

The cows calved between 1995 and 2009. According to the age at calving, the data were divided into five, four, and three groups within first, second, and third lactations, respectively (Table 1). Two seasons of calving were defined: October-March and April-September. 
Table 1. Number of lactations and test-day records by parity, calving age, and season of calving

\begin{tabular}{|c|c|c|c|}
\hline \multirow{2}{*}{$\begin{array}{l}\text { Lactation } \\
\text { number }\end{array}$} & \multirow{2}{*}{$\begin{array}{l}\text { Calving age, } \\
\text { months }\end{array}$} & \multicolumn{2}{|l|}{ Number of } \\
\hline & & lactations & test-day records \\
\hline \multirow[t]{5}{*}{1} & $18-24$ & 48,435 & 423,457 \\
\hline & $25-26$ & 55,154 & 491,215 \\
\hline & $27-28$ & 44,348 & 395,173 \\
\hline & $29-30$ & 30,076 & 266,809 \\
\hline & $31-48$ & 42,474 & 368,164 \\
\hline Total & & 220,487 & $1,944,818$ \\
\hline \multirow[t]{4}{*}{2} & $29-38$ & 57,556 & 489,671 \\
\hline & $39-41$ & 46,758 & 402,076 \\
\hline & $42-44$ & 34,892 & 301,009 \\
\hline & $45-65$ & 41,959 & 355,944 \\
\hline Total & & 181,165 & $1,548,700$ \\
\hline \multirow[t]{3}{*}{3} & $41-51$ & 41,690 & 349,561 \\
\hline & $52-55$ & 36,938 & 313,151 \\
\hline & $56-75$ & 50,146 & 418,395 \\
\hline Total & $41-75$ & 128,774 & $1,081,107$ \\
\hline \multirow{2}{*}{$\begin{array}{l}\text { Lactation } \\
\text { number }\end{array}$} & Season & Number of & \\
\hline & of calving & lactations & test-day records \\
\hline \multirow[t]{2}{*}{1} & April-September & 127,582 & $1,138,944$ \\
\hline & October-March & 92,905 & 805,874 \\
\hline Total & & 220,487 & $1,944,818$ \\
\hline \multirow[t]{2}{*}{2} & April-September & 102,652 & 892,921 \\
\hline & October-March & 78,513 & 655,779 \\
\hline Total & & 181,165 & $1,548,700$ \\
\hline \multirow[t]{2}{*}{3} & April-September & 72,010 & 617,329 \\
\hline & October-March & 56,764 & 463,778 \\
\hline Total & & 128,774 & $1,081,107$ \\
\hline
\end{tabular}

The following functions were fitted to the data on TD milk yields from each lactation:

1. Ali and Schaeffer (1987)

ALI:

$$
\begin{gathered}
y=b_{0}+b_{1} \cdot\left(\frac{t}{t_{\max }}\right)+b_{2} \cdot\left(\frac{t}{t_{\max }}\right)^{2}+b_{3} \cdot \ln \left(\frac{t_{\max }}{t}\right) \\
+b_{4} \cdot \ln ^{2}\left(\frac{t_{\max }}{t}\right)
\end{gathered}
$$

where: $t_{\max }=305$ or 400 .

2. Guo and Swalve (1995)

GUO:

$$
y=b_{0}+b_{1} \cdot \sqrt{t}+b_{2} \cdot \log (t)
$$

3. Wilmink (1987)

WIL:

$$
y=b_{0}+b_{1} \cdot t+b_{2} \cdot e^{-0.05 \cdot t}
$$

4. Normalized third-order Legendre polynomials LEG3:

$$
\begin{aligned}
y=b_{0}+ & b_{1} \cdot \sqrt{3} x+b_{2} \cdot \frac{\sqrt{5}}{2}\left(3 x^{2}-1\right) \\
& +b_{3} \cdot \frac{\sqrt{7}}{2}\left(5 x^{3}-3 x\right)
\end{aligned}
$$

5. Normalized fourth-order Legendre polynomials LEG4:

$$
y=\mathrm{LEG} 3+\left[b_{4} \cdot \frac{3}{8}\left(35 x^{4}-30 x^{2}+3\right)\right]
$$

were:

$x=2 \cdot \frac{t-t_{\min }}{t_{\max }-t_{\min }}-1, t_{\text {min }}=5, t_{\max }=305$ or 400

4. In all functions, $t$ was DIM, $b_{0}, b_{1}, b_{2}, b_{3}$, and $b_{4}$ were parameters to be estimated, and $y$ was milk yield at DIM $t$.

A multiple-trait prediction (MTP) method was applied for fitting lactation curves (Schaeffer and Jamrozik, 1996). The parameters of "standard lactation curves" were estimated within 24 subclasses of lactation by age at calving by season of calving. To estimate the matrix containing variances and covariances among the curve parameters, only cows with first TD before 50 DIM and minimum 9 TD records per lactation were considered. Standard lactation curves (305-d) and extended lactation curves (400-d) were fitted for cows in each of the first three parities.

The errors $\left(e_{i}\right)$ were calculated as the differences between the real $\left(y_{i}\right)$ and estimated $(\hat{y})$ milk yields $\left(e_{i}=y_{i}-\hat{y}_{i}\right)$. For each lactation curve model, the following criteria of the goodness of fit were applied:

1. Mean absolute error $\left(M A E=\Sigma \mid e_{i} / n\right)$,

2. Mean squared error $\left(M S E=\Sigma e_{i}^{2} / n\right)$,

3. Pearson's correlation between the real and estimated milk yields (R), which quantifies the degree of association between the real and estimated values,

4. Quotient between the error sum of squares and the observed sum of squares:

$$
\left(Q=100 \cdot \Sigma e_{i}^{2} / \Sigma y_{i}^{2}\right)
$$

lower values of this criterion indicated a closer similarity between the real and estimated values.

5. Percentage of outliers, i.e., estimated negative milkyields (EXLO) or very high, exceeding $85 \mathrm{~kg}$ milk yields (EXHI); negative estimates were considered biologically impossible and yields above $85 \mathrm{~kg}$ were omitted as a result of edits applied to data in the SYMLEK system.

The authors' dedicated scripts written in the AWK programming language, the MTP programs written by Dr. Janusz Jamrozik, and SAS/STAT procedures (SAS, 2004) were used for data editing and calculations. 


\section{Results}

Table 2 shows the values of different criteria used for comparing various models of 305-d lactation curves. For all models, the mean absolute error (MAE) and mean squared error (MSE) increased with lactation number. Within each of the three lactations, the differences in MAE and MSE were smallest for the ALI and LEG4 functions. The correlation values $(\mathrm{R})$ between the real and estimated milk yields were high for all models $(\mathrm{R}>0.94)$. Slightly lower correlations were found when fitting first-lactation curves. The Q criterion gave the lowest values when lactation was modeled by five-parameter functions (ALI and LEG4), and the highest, for three-parameter models (GUO and WIL). According to the four above criteria (MAE, MSE, R, and Q), the more parameters a model contained, the better fit to the data it offered. The proportion of estimated negative milk yields (EXLO) ranged between $0.006 \%$ and $0.732 \%$ of the records, with the smallest scores being obtained for the GUO and WIL models, and the biggest for LEG4.

Table 2. Comparison of standard (305-d) lactation curves fitted to test-day milk yields using different criteria of goodness of fit

\begin{tabular}{llllllll}
\hline \multicolumn{2}{l}{ Lactation } & $\mathrm{MAE}^{2}$ & $\mathrm{MSE}^{3}$ & $\mathrm{R}^{4}$ & $\mathrm{Q}^{5}$ & $\begin{array}{l}\text { EXLO } \\
6 \%\end{array}$ & $\begin{array}{l}\mathrm{EXHI}^{7} \\
\%\end{array}$ \\
\hline \multicolumn{2}{l}{ model } & number \\
$\mathrm{ALI}$ & 1 & 1.32 & 3.52 & 0.965 & 0.89 & 0.234 & $1.43 \cdot 10^{-4}$ \\
& 2 & 1.51 & 4.57 & 0.969 & 0.93 & 0.403 & $8.78 \cdot 10^{-4}$ \\
& 3 & 1.57 & 4.93 & 0.968 & 0.94 & 0.510 & $7.43 \cdot 10^{-4}$ \\
GUO & 1 & 1.69 & 5.39 & 0.946 & 1.37 & 0.008 & 0 \\
& 2 & 1.95 & 7.25 & 0.951 & 1.47 & 0.011 & 0 \\
& 3 & 2.04 & 7.92 & 0.948 & 1.51 & 0.012 & 0 \\
LEG3 & 1 & 1.43 & 4.06 & 0.959 & 1.03 & 0.146 & 0 \\
& 2 & 1.63 & 5.32 & 0.964 & 1.08 & 0.258 & 0 \\
& 3 & 1.71 & 5.79 & 0.962 & 1.11 & 0.335 & 0 \\
LEG4 & 1 & 1.30 & 3.36 & 0.967 & 0.85 & 0.335 & $4.22 \cdot 10^{-5}$ \\
& 2 & 1.48 & 4.39 & 0.971 & 0.89 & 0.585 & 0 \\
& 3 & 1.54 & 4.75 & 0.969 & 0.91 & 0.732 & 0 \\
WIL & 1 & 1.69 & 5.42 & 0.946 & 1.37 & 0.006 & 0 \\
& 2 & 1.95 & 7.32 & 0.95 & 1.48 & 0.011 & $1.83 \cdot 10^{-6}$ \\
& 3 & 2.05 & 8.02 & 0.947 & 1.53 & 0.014 & 0 \\
\hline
\end{tabular}

1 ALI - Ali and Schaeffer, GUO - Guo, LEG3 - third-order Legendre polynomials, LEG4 - fourth-order Legendre polynomials, WIL - Wilmink; ${ }^{2} \mathrm{MAE}$ - mean absolute error; ${ }^{3} \mathrm{MSE}$ - mean square error; ${ }^{4} R$ - correlation between the real milk yields and the estimated milk yields; ${ }^{5} \mathrm{Q}$ - quotient between the error sum of squares and the observed sum of squares; ${ }^{6}$ EXLO - estimated milk yields $\leq 0 \mathrm{~kg}$; ${ }^{7} \mathrm{EXHI}-$ estimated milk yields $>85 \mathrm{~kg}$

The percentage of milk yields higher than $85 \mathrm{~kg}$ (EXHI) was close to zero in all cases, indicating that the five models estimated such outliers very rarely.
The values of MAE and MSE calculated for extended (400-d) lactations (Table 3) were higher than for standard lactations, but exhibited a similar pattern in that they increased in second and third lactations. The values of MAE and MSE were smallest for the ALI function, slightly higher for LEG3 and LEG4, and highest for GUO and WIL.

Table 3. Comparison of extended (400-d) lactation curves fitted to test-day milk yields using different criteria of goodness of fit

\begin{tabular}{|c|c|c|c|c|c|c|c|}
\hline \multicolumn{2}{|c|}{$\begin{array}{l}\text { Lactation } \\
\text { model }^{1} \text { number }\end{array}$} & \multirow{2}{*}{$\begin{array}{l}\mathrm{MAE}^{2} \\
\mathrm{~kg} \\
1.39\end{array}$} & \multirow{2}{*}{$\begin{array}{l}\mathrm{MSE}^{3} \\
\mathrm{~kg}\end{array}$} & \multirow{2}{*}{$\begin{array}{l}R^{4} \\
0.957\end{array}$} & & \multirow{2}{*}{$\begin{array}{l}\text { EXLO } 6 \\
\% \\
1.506\end{array}$} & \multirow{2}{*}{$\begin{array}{l}\begin{array}{l}\text { EXHI } \\
\%\end{array} \\
1.26 \cdot 10^{-3}\end{array}$} \\
\hline $\mathrm{ALI}^{1}$ & 1 & & & & & & \\
\hline & 2 & 1.56 & 5.3 & 0.964 & 1.11 & 2.369 & $3.61 \cdot 10^{-3}$ \\
\hline & 3 & 1.62 & 5.63 & 0.963 & 1.11 & 2.604 & $5.81 \cdot 10^{-3}$ \\
\hline \multirow[t]{3}{*}{ GUO $^{1}$} & 1 & 1.73 & 5.78 & 0.942 & 1.5 & 0.278 & 0 \\
\hline & 2 & 1.98 & 7.56 & 0.949 & 1.58 & 0.668 & 0 \\
\hline & 3 & 2.07 & 8.19 & 0.946 & 1.61 & 0.842 & 0 \\
\hline \multirow[t]{3}{*}{ LEG31 } & 1 & 1.51 & 5.12 & 0.949 & 1.33 & 1.404 & $1.29 \cdot 10^{-3}$ \\
\hline & 2 & 1.69 & 6.31 & 0.957 & 1.32 & 2.235 & $3.15 \cdot 10^{-3}$ \\
\hline & 3 & 1.76 & 6.76 & 0.956 & 1.33 & 2.423 & $6.02 \cdot 10^{-3}$ \\
\hline \multirow[t]{3}{*}{ LEG4 ${ }^{1}$} & 1 & 1.45 & 6.85 & 0.933 & 1.78 & 3.246 & $2.08 \cdot 10^{-2}$ \\
\hline & 2 & 1.61 & 7.76 & 0.948 & 1.62 & 3.815 & $3.79 \cdot 10^{-2}$ \\
\hline & 3 & 1.66 & 8.00 & 0.948 & 1.57 & 4.239 & $5.29 \cdot 10^{-2}$ \\
\hline \multirow[t]{3}{*}{ WIL $^{1}$} & 1 & 1.73 & 5.81 & 0.942 & 1.51 & 0.439 & 0 \\
\hline & 2 & 1.98 & 7.61 & 0.949 & 1.59 & 1.107 & $1.39 \cdot 10^{-6}$ \\
\hline & 3 & 2.07 & 8.27 & 0.946 & 1.63 & 1.363 & 0 \\
\hline
\end{tabular}

${ }^{1}$ As in Table 2

In each of the first three lactations, the highest correlations $(\mathrm{R})$ between the real and estimated milk yields were noted for the ALI function; for the other models (GUO, LEG3, LEG4 and WIL) the R values were slightly smaller. According to the Q criterion, the ALI model performed best, and LEG4 was worst. With each of the five models, the estimated proportion of negative milk yields (EXLO) was larger for 400-d than for 305-d lactations. The percentage of EXLO increased with lactation number. As for standard lactations, the EXLO values were lowest when using the GUO and WIL functions, and highest for LEG4. Very high milk yields (EXHI) estimated by means of ALI, LEG3 and LEG4 were rarely observed. The percentages of EXHI for three-parameter functions (GUO and WIL) demonstrate that these two functions very rarely overestimated daily milk yields. 


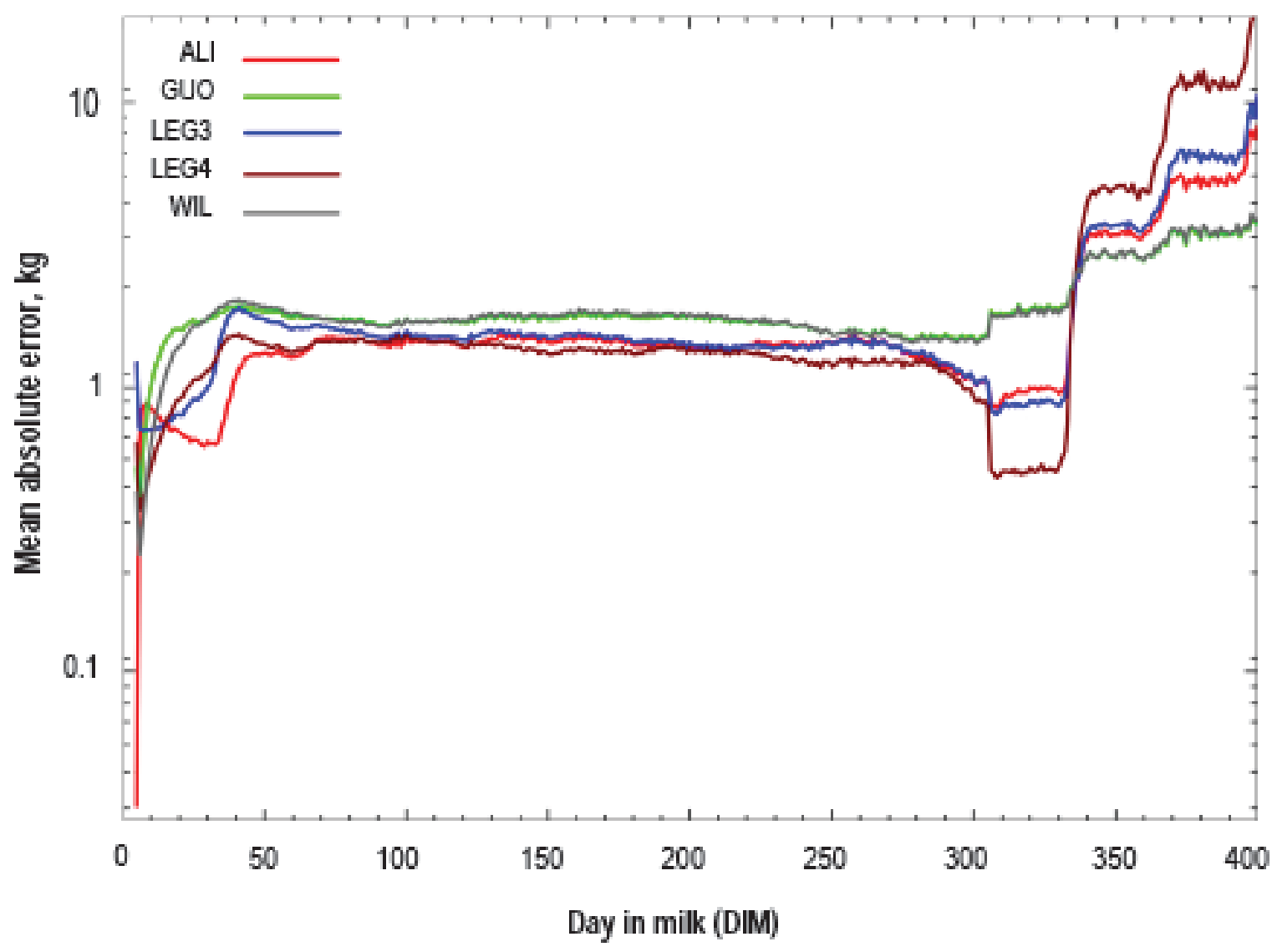

Figure 1. Distribution of mean absolute error for DIM 5 to 400 of first-parity, and for Ali and Schaeffer (ALI), Guo (GUO) and Wilmink (WIL) functions, and third-order (LEG3) and fourth-order (LEG4) Legendre polynomials

Figure 1 shows how the values of mean absolute error (MAE) changed over DIM in the first lactation. For all five models fitted to the data, the MAE values followed a similar pattern: i.e., they were low at early stages of lactation (5-40 DIM), slightly higher but at a constant level (about $2-3 \mathrm{~kg}$ ) between 40 and 305 DIM, and highest after 330-d. The exception was MAE lowered to values below $1 \mathrm{~kg}$ between 306-330 DIM, calculated for yields estimated using the ALI, LEG3, and LEG4 models. The goodness of fit was worse after 305 DIM because of a small number of data available for this period of lactation. The data on TD yields between 305 and 350 DIM constituted about $4 \%$, and on those between 350 and 400 DIM, less than $2 \%$ of all the available data. For the second and third parties, the distributions of daily MAE were similar.

\section{Discussion}

Correlation (R) between observed and predicted milk yields is the most commonly used criterion of the goodness of fit for a lactation curve model. According to the $\mathrm{R}$ values, all of the lactation curve models compared in this study were fitted to TD data with a very high level of accuracy. The correlations shown in Table 2 are lower than those reported by Olori et al. (1999) for the ALI (0.998), GUO (0.980), and WIL (0.996) functions. It should be stressed, however, that the latter authors fitted lactation curves to weekly yields, and used only data on the first lactations of cows from one herd kept under a uniform system of feeding and management. By contrast, Quinn et al. (2005) using weekly yields for modeling lactation curves obtained lower $\mathrm{R}$ values (ALI 0.82 , GUO 0.80, and WIL 0.77) as compared with our results. All correlations calculated by Silvestre et al. (2006) for various lactation curve models, including ALI, WIL, LEG3, and LEG4, exceeded 0.9. Depending on the first TD (10 or 24 DIM) and testing method (A4 or A8), the correlations computed by Guo and Swalve (1995) ranged between 0.83 and 0.87 for the GUO model, and between 0.86 and 0.89 for the WIL function. When modeling the lactation curve using GUO and WIL, they obtained the MAE values of 1.49-1.59 and 1.22-1.55, respectively. Judging by the R and MAE criteria, Guo and Swalve (1995) concluded that GUO performed best among three-parameter functions, while WIL, 
modified to a five-parameter function, was the best of all the functions they studied.

Silvestre et al. (2006) who compared lactation curve models using the $\mathrm{Q}$ quotient noted higher values for ALI, WIL, LEG3, and LEG4 (1.9 to 2.1) than those obtained in our study, which means that their estimated yields were worse fitted to real data. When the first TD occurred later in a lactation, i.e. on 30,60 or $90 \mathrm{DIM}$, the Q values in their study were significantly higher than in the case of starting data collection shortly after calving. The latter authors observed that models such as ALI or WIL were strongly affected by the structure of data. A reduction in sample size, especially if parallel to an increase in the interval between calving and the first yield, significantly influenced the goodness of fit of parametric models. When the first TD occurred after 30 DIM, then polynomials (LEG3 or LEG4) were a better choice as a model for fitting lactation curves.

Silvestre et al. (2006) also found that the functions they compared did not differ in terms of EXLO and EXHI when all data were considered: there were no estimates of negative milk yields, and rare estimates of very high milk yields $(>50 \mathrm{~kg})$. The percentage of estimated milk yields greater than $50 \mathrm{~kg}$ increased to $9.61 \%$ when they used a small number of TD yields for fitting lactation curves, and the milk yields was first recorded 90 days post partum.

Most measures of the goodness of fit used in this study indicated that a larger number of parameters in a model ensures its better fit to the data. Namely, five-parameter functions (ALI and LEG4) were the most suitable for describing the shape of the lactation curve, a four-parameter function (LEG3) was slightly worse, whereas three-parameter functions (GUO and WIL) were the worst. Our results demonstrating the best performance of the ALI and LEG4 models confirmed those of Silvestre et al. (2006); the latter authors also mentioned that all of the models they tested (including WIL) performed acceptably. According to the results of Quinn et al. (2005), who applied five different models (including ALI, GUO, and WIL) for modeling lactation curves, the ALI function, modified to a four-parameter model, gave the best fit to the data; the ALI model was also the best for describing total milk yield. Druet et al. (2003) found that regression splines are useful for modeling lactation curves as they bring the following advantages: a limited number of required parameters, good flexibility, smoothness, and limited sensitivity to data. The latter authors also underlined that in choosing the best function, goodness of fit must be weighed against other properties such as flexibility or robustness, and computational considerations must also be taken into account. This explains the existing wide variation in models across studies and countries. Macciotta et al. (2005) and Macciotta et al. (2010) came to similar conclusions and recommended functions with high flexibility, such as high-order orthogonal polynomials (e.g., LEG4) or cubic splines, as more suitable than parametric models (e.g., ALI or WIL).

The results of the present study showed that the most adequate function for modeling longer (400-d) lactations in the Polish population of Holstein-Friesians was ALI. Legendre polynomials (LEG3 and LEG4) performed slightly worse, and functions with fewer parameters, such as WIL and GUO, were found to be the worst. Dematawewa et al. (2007), comparing nine models, different from our functions, observed that all of them described extended lactations well, and recommended functions such as those in Rook et al. (1993) or Wood (1967) as sufficiently good for modeling extended lactations in cows. They also pointed out that the choice of a particular function depended on the potential future use of the fitted lactation curves. Dematawewa et al. (2007) found that all nine models were able to predict daily yields within an error margin of $\pm 2 \mathrm{~kg}$ of milk for over $90 \%$ of extended lactations. The prediction errors were less than $10 \%$ of the magnitude of daily yields, suggesting that even three-parameter functions can be used to model extended lactations with reasonable accuracy.

Vargas et al. (2000) compared different lactation curve models for their ability to accurately predict daily milk yields in standard and extended (to 18 months) lactations. Of the nine functions, they chose the diphasic model (Grossman and Koops, 1988) as best with respect to the criteria of goodness of fit they used. Vargas et al. (2000) reported that the models fitted to standard (305-d) and extended (18 months) lactations ranked differently, indicating that more research is needed on the modeling of extended lactations.

\section{Conclusions}

Five mathematical functions for modeling the lactation curve in cattle were compared for accuracy of predicting milk yields from test-day records. The results indicate that five-parameter functions, Ali and Schaeffer (ALI), and fourth-order Legendre polynomials (LEG4) ensure a superior fit to the data, although the performance of models containing 
fewer parameters is also acceptable. The fourth-order Legendre polynomials (LEG4) can be recommended for modeling 305-d lactations, and the Ali and Schaeffer (ALI) function, for extended lactations.

\section{Acknowledgment}

The use of Dr. Janusz Jamrozik's programs is gratefully acknowledged.

\section{References}

Ali T.E., Schaeffer L.R., 1987. Accounting for covariances among test day milk yields in dairy cows. Can. J. Anim. Sci. 67, 637-644

Bohmanova J., Miglior F., Jamrozik J., Misztal I., Sullivan P.G., 2008. Comparison of random regression models with Legendre polynomials and linear splines for production traits and somatic cell score of Canadian Holstein cows. J. Dairy Sci. 91, 3627-3638

Cole J.B., Null D.J., VanRaden P.M., 2009. Best prediction of yields for long lactations. J. Dairy Sci. 92, 1796-1810

Dematawewa C.M.B., Pearson R.E., VanRaden P.M., 2007. Modeling extended lactations of Holsteins. J. Dairy Sci. 90, 3924-3936

Druet T., Jaffrezic F., Boichard D., Ducrocq V., 2003. Modeling lactation curves and estimation of genetic parameters for first lactation test-day records of French Holstein cows. J. Dairy Sci. 86, 2480-2490

Grossman M., Koops W.J., 1988. Multiphasic analysis of lactation curves in dairy cattle. J. Dairy Sci. 71, 1598-1608

Guo Z., Swalve H.H., 1995. Modelling of lactation curve as a sub-model in the evaluation of test day records. Interbull Meeting, Prague, Czech Republic. Interbull Bulletin. 11, 4-7

Macciotta N.P.P., Vicario D., Cappio-Borlino A., 2005. Detection of different shapes of lactation curve for milk yield in dairy cattle by empirical mathematical models. J. Dairy Sci. 88, 1178-1191
Macciotta N.P.P., Miglior F., Dimauro C., 2010. Comparison of parametric orthogonal, and spline functions to model individual lactation curves for milk yield in Canadian Holsteins. Ital. J. Anim. Sci. 9, 460-464

Norman H.D., VanRaden P.M., Wright J.R., Clay J.S., 1999. Comparison of test interval and best prediction methods for estimation of lactation yield from monthly, a.m-p.m, and trimonthly testing. J. Dairy Sci. 82, 438-444

Olori V.E., Brotherstone S., Hill W.G., McGuirk B.J., 1999. Fit of standard models of the lactation curve to weekly records of milk production of cows in a single herd. Livest. Prod. Sci. 58, 55-63

Ptak E., Schaeffer L.R., 1993. Use of test day yields for genetic evaluation of dairy sires and cows. Livest. Prod. Sci. 34, 23-34

Quinn N., Killen L., Buckley F., 2005. Empirical algebraic modelling of lactation curves using Irish data. Irish J. Agr. Food Res. 44, 1-13

Rook A.J., France J., Dhanoa M.S., 1993. On the mathematical description of lactation curves. J. Agr. Sci. 121, 97-102

SAS, 2004. SAS ® 9.1.2 Qualification Tools User's Guide. SAS Institute Inc. Cary, NC

Schaeffer L.R., Jamrozik J., 1996. Multiple-trait prediction of lactation yields for dairy cows. J. Dairy Sci. 79, 2044-2055

Silvestre A.M., Petim-Batista F., Colaco J., 2006. The accuracy of seven mathematical functions in modeling dairy cattle lactation curves based on test-day records from varying sample schemes. J. Dairy Sci. 89, 1813-1821

VanRaden P.M., 1997. Lactation yields and accuracies computed from test day yields and (co)variances by best prediction. J. Dairy Sci. 80, 3015-3022

Vargas B., Koops W.J., Herrero M., Van Arendonk J.A.M., 2000. Modeling extended lactations of dairy cows. J. Dairy Sci. 83, 1371-1380

Wilmink J.B.M., 1987. Adjustment of test-day milk, fat and protein yield for age, season and stage of lactation. Livest. Prod. Sci. 16, $335-348$

Wood P.D.P., 1967. Algebraic model of the lactation curve in cattle. Nature 216, 164-165 